\title{
On the Structure of Protonated Methane
}

\author{
Albert J. R. Heck, Leo J. de Koning, and Nico M. M. Nibbering \\ Institute of Mass Spectrometry, University of Amsterdam, Amsterdam, The Netherlands
}

\begin{abstract}
Results of a Fourier transform-ion cyclotron resonance study are reported concerning the reactivity of protonated perdeuteromethane and deuteronated methane, generated under varying pressurc conditions in an external chemical ionization ion source, toward ammonia. The competition between proton and deuteron transfer from both protonated perdeuteromethane and deuteronated methane to ammonia exhibits chemically distinguishable hydrogens. The chemical hehavior of protonated methane appears to be compatible with the theoretically predicted stable structure with $C_{S}$ symmetry, involving a three-center two-electron bond associating two hydrogens and the carbon atom. Interconversion of this structure due to exchange between one of these hydrogens and one of the three remaining hydrogens appears to be a fast process that is induced by interactions with the chemical ionization gas. (J Am Soc Mass Spectrom 1991, 2, 453-458)
\end{abstract}

$P$ rotonated methane has been one of the first reactio $n$ products observed in gas-phase ionmolecule chemistry $[1,2]$, whereas in the condensed phase it has been claimed as a reactive intermediate in strongly acidic alkane solutions [3]. Because of the convenience of generation and its strong acidity in the gas phase it has found a wide application as a chemical ionization reagent in mass spectrometric analysis [4]. Since its early generation protonated methane has been the subject of many experimental and theoretical studies that have been set up to gain insight in both the mechanism of formation and the structure of this hypervalent species.

Protonated methane can be generated in an atmosphere of methane via a bimolecular reaction between ionized methane and methane, as shown in eq 1.

$$
\mathrm{CH}_{4}^{+\cdot}+\mathrm{CH}_{4} \rightarrow \mathrm{CH}_{5}^{+}+\mathrm{CH}_{3}
$$

Isotopic labeling [5], crossed beam [6], threshold ion electron coincidence (TESICO) [7], and temperature variable flowing afterglow studies [8] indicate that the reaction proceeds via an intermediate $\left[\mathrm{CH}_{4}\right.$ $\left.\cdots \mathrm{CH}_{4}\right]^{{ }^{+-}}$complex in which either proton transfer from the ionized methane to the methane molecule or hydrogen transfer from the methane molecule to ionized methane is followed by dissociation of the complex leading to the formation of protonated methane and a methyl radical. Under conditions where both the internal and translational energies of the reactants are low, the lifetime of the intermediate complex increases, thereby allowing hydrogen exchange be-

Address reprint requests to N, M. M, Nibbering, Institute of Mass Spectrometry, University of Amsterdam, Nieuwe Achtergracht 129, 1018 WS Amsterdam, The Netherlands. tween the two $\mathrm{CH}_{4}$ moieties prior to the formation of free protonated methane [8]. Evidence that the intermediate complex can exist as a long-lived species has been derived from its observation as a product ion in the multistep molecular exchange reaction between the cationic dimer of krypton and methane [9].

In the formation of protonated methane, proton transfer from the ionized methane to the methane molecule is the dominant reaction channel under all experimental conditions, whereas hydrogen transfer from the methane molecule to ionized methane gains importance upon decreasing the total energy of the reaction system [8]. Bimolecular hydrogen exchange in the intermediate complex is observed to compete with the direct proton transfer only at extremely low temperatures [8] or low translational energies [6].

Quantum mechanical calculations have been used widely as a tool for structural analysis of small cations. For the $\mathrm{CH}_{4}$ system, calculations denote a tetrahedral symmetry for neutral methane, a $C_{2 v}$ symmetry for its radical cation [10], and a planar $C_{2 v}$ symmetry for the dication that apparently can be regarded as a complex between $\mathrm{CH}_{2}^{2+}$ and $\mathrm{H}_{2}$ [11]. Also, the structure of protonated methane has been the subject of several theoretical calculations over many years [10, 12-14]. The most stable structure has been calculated to have $C_{s}$ symmetry as depicted in Figure 1 , with two equivalent hydrogens in the three-center two-electron bond, whereas the remaining three hydrogens are approximately equivalent [14]. Hence, protonated methane may be regarded as a hypervalent species.

The predicted structure suggests that the proton has inserted into one of the $\sigma \mathrm{C}-\mathrm{H}$ bonds of methane to form a three-center two-electron bond with the carbon and the hydrogen atom. Furthermore, the activation energy associated with exchange between 


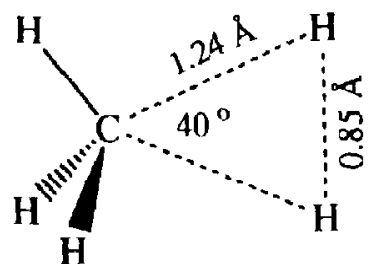

Figure 1. Theoretically predicted minimum energy structure of protonated methane.

the hydrogens in the three-center two-electron bond and the remaining hydrogens has been calculated to be between 1 and $16 \mathrm{kcal} / \mathrm{mol}$ [13], assuming that the exchange process proceeds via a transition state of $C_{2 v}$ or $D_{3 h}$ symmetry.

Experimental mass spectrometric studies concerning the structure of protonated methane have been focused on its chemical reactivity in proton transfer reactions toward acceptor molecules. Already in 1974, Sefcik et al. [15] conducted an ion cyclotron resonance (ICR) study to probe the chemical identity of the hydrogens in both $\mathrm{CH}_{4} \mathrm{D}^{+}$and $\mathrm{CD}_{4} \mathrm{H}^{+}$, generated from a gaseous mixture of $\mathrm{CH}_{4}$ and $\mathrm{CD}_{4}$, by establishing the selectivity of proton versus deuteron transfer to a series of acceptor molecules with varying proton affinities. For the series of acceptor molecules an average ratio of proton over deuteron transfer of 2.5 was found for the reactions of $\mathrm{CH}_{4} \mathrm{D}^{+}$, whereas a ratio of 0.7 was determined for the reactions with $\mathrm{CD}_{4} \mathrm{H}^{+}$. Because these values significantly differed from the statistical value of 4 and 0.25 , respectively, assuming a random distribution of hydrogen and deuterium or chemically equivalent hydrogens in protonated methane, Sefcik et al. concluded that "the reactions of methonium ions formed in the low energy electron impact ionization of $\mathrm{CH}_{4} / \mathrm{CD}_{4}$ mixtures are compatible with a methonium ion of $\mathrm{C}_{\mathrm{s}}$ structure in which intramolecular rearrangement does not occur." Yet the two ratios were established during a double resonance excitation of the $\mathrm{CH}_{4} \mathrm{D}^{+}$and $\mathrm{CD}_{4} \mathrm{H}^{+}$ions, respectively, of which the selectivity does not exclude contributions to the product ions due to reactions of isobaric ions.

One year later Smith and Futrell [16] reported a similar study performed on a tandem ICR mass spectrometer. Here, both $\mathrm{CH}_{4} \mathrm{D}^{+}$and $\mathrm{CD}_{4} \mathrm{H}^{+}$were generated from a gaseous mixture of $\mathrm{CH}_{4}$ and $\mathrm{CD}_{4}$ in a chemical ionization source. The ions were extracted from the source, subsequently mass selected in a magnetic sector and injected into a differentially pumped ICR cell, where they were allowed to transfer a proton or deuteron to the acceptor molecule under low conversion, single collision conditions. An average ratio of proton over deuteron transfer of 4.5 was found for the reactions of $\mathrm{CH}_{4} \mathrm{D}^{+}$, whereas a ratio of
0.3 was determined for the reactions with $\mathrm{CD}_{4} \mathrm{H}^{+}$. This prompted Smith and Futrell to conclude that "the results are clearly consistent with a randomized model" and, "while we cannot explain the origin of the apparently conflicting results, it is clear that the present experiments do not support the specific structure model for $\mathrm{CH}_{5}^{+}$proposed by Sefcik et al". Yet, also the experiments of Smith and Futrell [16] do not exclude contributions to the product ions due to reactions of isobaric ions because of poor mass resolution of ion selection [17]. Evidently, the above controversy is caused by the complexity of the structural probe which demands ideally a full control over all experimental parameters.

Since the above early experiments were conducted, mass spectrometry has experienced a turbulent development that seems to justify verification of the earlier results. To this end, a related study has been set up to probe the chemical nature of the hydrogens in protonated methane making use of a Bruker Spectrospin CMS 47X Fourier transform ICR (FT-ICR) mass spectrometer (Fällanden, Switzerland) equipped with an external ion source, which permits generation of protonated methane under relatively well controlled chemical ionization conditions as well as ultrahigh selectivity of reactant ion selection [18] and product ion detection.

\section{Experimental}

A detailed description of the Bruker Spectrospin CMS 47X FT-ICR mass spectrometer used in this study and the general operating procedures have been reported previously $[18,19]$. The temperature in the external ion source was kept below $450 \mathrm{~K}$, whereas the FT-ICR cell was kept at room temperature. Unless stated otherwise, the other experimental conditions were similar to those reported in a previous study [19].

\section{Materials}

All chemicals employed were commercially available and used without further purification. Perdeuteromethane with a label content of $99 \% \mathrm{D}$ was purchased from Cambridge Isotope Laboratories.

\section{Results}

In order to probe the chemical nature of the hydrogens in isotopically labeled protonated methane, the probability of intramolecular and/or intermolecular hydrogen/deuterium randomization within the collision complex between protonated methane and the proton acceptor molecule must be minimized. Intramolecular hydrogen/deuterium exchange with a 
calculated barrier of maximally $16 \mathrm{kcal} / \mathrm{mol}$ [13] can easily be fueled by the solvation energy gained upon formation of the reaction complex which also may drive the reverse proton transfer, resulting in intermolecular hydrogen/deuterium exchange. This can be avoided by studying the proton transfer to a molecule with a very large proton affinity by which the reverse proton transfer in the reaction complex becomes irreversible. Moreover, the accompanying negligible proton transfer barrier results in a very short lifetime of the reaction complex, as a consequence of which the intermolecular hydrogen/deuterium randomization cannot compete with the proton transfer. Moreover, the negligible proton transfer activation energy, compared to the total internal energy of the reaction system, suppresses isotope effects that kinetically may favor proton over deuteron transfer.

Amines seem to be the obvious proton acceptors that satisfy the above requirements. Unfortunately, the exothermicity of the proton transfer energetically enables loss of a hydrogen molecule from the protonated amine, as has been observed for the reaction between $\mathrm{CH}_{4} \mathrm{D}^{+}$and methylamine, shown in eq 2 , where the exothermicity of the overall reaction resulting in imine ions amounts to $50 \mathrm{kcal} / \mathrm{mol} \mathrm{[20].}$

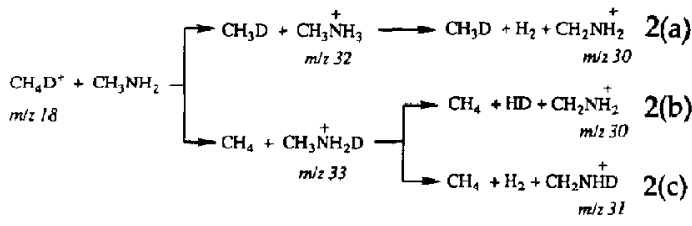

Because the selectivity of $\mathrm{H}_{2}$ loss relative to that of $\mathrm{HD}$ loss from $\mathrm{CH}_{3} \mathrm{NH}_{2} \mathrm{D}^{+}$is not known, the ratio of the ion abundances of the protonated and deuteronated methylamine product ions does not necessarily reflect the branching ratio of proton over deuteron transfer in the initial reaction step. For this reason the collisionally controlled proton transfer to ammonia with a rate constant of $2.3^{*} 10^{-9} \mathrm{~cm}^{3}$ molecule ${ }^{-1} \mathrm{~s}^{-1}$ [21] has been taken as a probe to monitor the identity of the hydrogens in protonated methane because hydrogen molecule loss from the ammonium ion requires an energy of $155 \mathrm{kcal} / \mathrm{mol}$ [20], whereas the exothermicity of the initial proton transfer is $72.4 \mathrm{kcal} / \mathrm{mol}$ [20], ensuring a kinetically stable ammonium product ion under the experimental conditions.

The experiments were initiated with the generation of $\mathrm{CH}_{4} \mathrm{D}^{+}$and $\mathrm{CD}_{4} \mathrm{H}^{+}$from a $1: 1$ mixture of $\mathrm{CH}_{4}$ and $\mathrm{CD}_{4}$ in the external ion source by using electrons with energies close to the ionization threshold energy of methane (12.51 eV [20]). By varying the pressure, the average number of primary collisions, $n$, between ionized methane and methane was controlled between 0 and 0.6 [19]. Under these conditions collisionally induced hydrogen/deuterium randomization in the isotopically labeled protonated methanes in the chemical ionization plasma was minimized (see below). Inevitably, these conditions resulted in an unfavorably low yield of $\mathrm{CH}_{4} \mathrm{D}^{+}$and $\mathrm{CD}_{4} \mathrm{H}^{+}$ions. The ions from the chemical ionization plasma were injected for a period of $50 \mathrm{~ms}$ into the differentially pumped FT-ICR cell which was filled with gaseous ammonia up to a pressure of $3 \times 10^{-8} \mathrm{mbar}$.

Due to the low conversion the most dominant ions from the chemical ionization plasma were detected to be the primary ions $\mathrm{CH}_{3}^{+}, \mathrm{CH}_{4}^{+}, \mathrm{CD}_{3}^{+}$, and $\mathrm{CD}_{4}^{+*}$. Consequently, the presence of $\mathrm{CD}_{3}^{+}$and ${ }^{13} \mathrm{CD}_{4}^{+*}$ in the chemical ionization plasma required high resolution selection of the low abundant isobaric $\mathrm{CH}_{4} \mathrm{D}^{+}$. and $\mathrm{CD}_{4} \mathrm{H}^{+}$ions, respectively. No $\mathrm{CH}_{3} \mathrm{D}_{2}^{+}$and $\mathrm{CH}_{2} \mathrm{D}_{3}^{+}$ions were detected. This high resolution selection was realized following a previously described procedure [18].

The result of the selection of $\mathrm{CH}_{4} \mathrm{D}^{+}$is shown in Figure 2. Figure 2a represents the mass spectrum of the ions with a nominal mass of $18 \mathrm{u}$ after ejection of all other ions that were initially trapped in the FT-ICR cell. The presence of $\mathrm{NH}_{4}^{+}$revealed that the proton transfer to $\mathrm{NH}_{3}$ had already progressed during the period of $50 \mathrm{~ms}$ in which the ions from the external source were injected into the cell. In Figure $2 b$, the effective removal of the $\mathrm{CD}_{3}^{+}$ions is demonstrated for which a mass resolution of ion ejection was required of at least 6000 . Finally, the high resolution removal of $\mathrm{NH}_{4}^{+}$resulted in the selection of the $\mathrm{CH}_{4} \mathrm{D}^{+}$ions, as shown in Figure 2c. Subsequently, the selected $\mathrm{CH}_{4} \mathrm{D}^{+}$ions were allowed to transfer a proton or deuteron to ammonia for a period of only $250 \mathrm{~ms}$, again to ensure low conversion single collision conditions that were required in this case to prevent deuterium/hydrogen exchange reactions between product ions and ammonia.

Following a similar procedure, the $\mathrm{CD}_{4} \mathrm{H}^{+}$ions were selected and allowed to react with ammonia. The product ions $\mathrm{NH}_{4}^{+}$and $\mathrm{NH}_{3} \mathrm{D}^{+}$were detected in helerodyne mode with a mass resolution of 250,000 (FWHH), which was more than sufficient to discriminate between reactant ion $\mathrm{CH}_{4} \mathrm{D}^{+}$and product ion $\mathrm{NH}_{4}^{+}$, both having a nominal mass of $18 \mathrm{u}$ (see also Figure 2), and to discriminate between $\mathrm{NH}_{3} \mathrm{D}^{+}$and $\mathrm{H}_{3} \mathrm{O}^{+}$, possibly formed in the reaction between the isotopically labeled protonated methanes and gaseous background water molecules. $\mathrm{No}_{3} \mathrm{O}^{+}$or any other product ions apart from $\mathrm{NH}_{4}^{+}$and $\mathrm{NH}_{3} \mathrm{D}^{+}$were detected. Relative product ion abundances were now determined from the scaled heterodyne FT-spectra, each recorded under identical conditions. The results obtained for the reactions of both $\mathrm{CH}_{4} \mathrm{D}^{+}$and $\mathrm{CD}_{4} \mathrm{H}^{+}$ are summarized in Figure 3, which graphically displays the product ion ratio $\left[\mathrm{NH}_{4}^{+}\right] /\left[\mathrm{NH}_{3} \mathrm{D}^{+}\right]$determined as a function of the average number of primary collisions in the external ion source, $n$, between ionized methane and methane. From statistical analysis of the results obtained over three independent experi- 

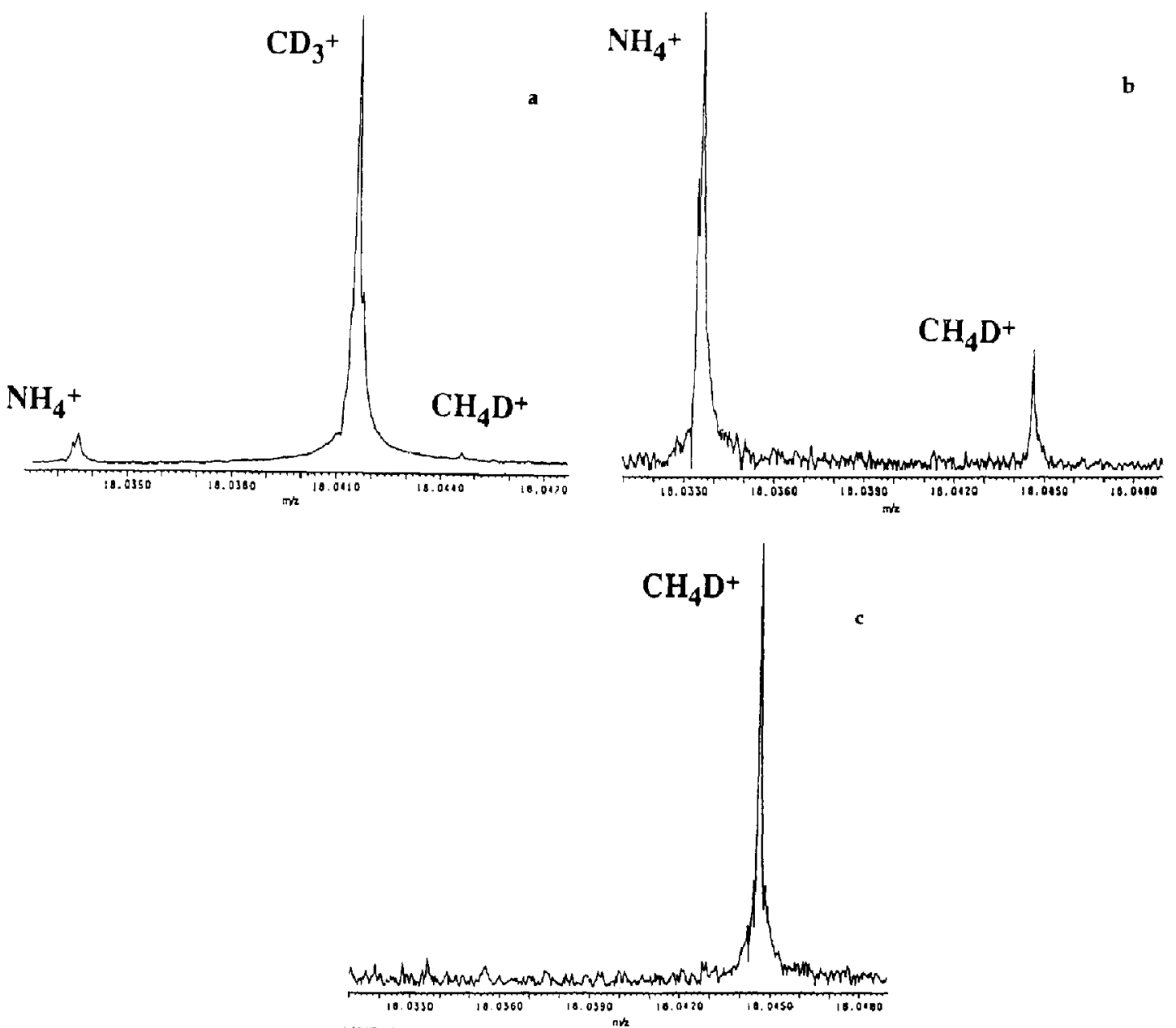

Figure 2. High resolution selection of $\mathrm{CH}_{4} \mathrm{D}^{+}$ions. (a) FT-ICR mass spectrum of the ions with a numinal mass of $18 \mathrm{u}$ that were injected into the FT-ICR cell together with the product ions that were formed in the FT-ICR cell during the injection period of $50 \mathrm{~ms}$ due to reactions between injected ions and introduced ammonia at a pressure of $3 \times 10^{-8} \mathrm{mbar}$. All other ions outside the displayed mass range have been ejected from the FT.ICR cell. The response signal was sampled for 0.150 s. Fifty digitized response signals were accumulated prior to Fourier transformation. Mass resolution is better than 250,000 (FWHH). (b) As in (a), but additionally, high resolution ejection of $\mathrm{CD}_{3}^{+}$ions has been executed prior to detection. One hundred digitized response signals were accumulated prior to Fourier transformation. (c) As in (b), but additionally, high resolution ejection of $\mathrm{NH}_{4}^{+}$ions has been executed prior to detection.

ments, the error in the product ion ratios was estimated to be less than $10 \%$.

\section{Discussion}

From the results in Figure 3 it appears that upon minimizing the average number of primary ion collisions, $n$, in the external ion source both $\mathrm{CH}_{4} \mathrm{D}^{+}$and $\mathrm{CD}_{4} \mathrm{H}^{+}$transfer a proton or deuteron to ammonia with equal probability. Because under these low conversion conditions none of these ions prefer proton over deuteron transfer, significant kinetic isotope effects can be ruled out, as expected (see above). There- fore, the results imply that in protonated methane one of the hydrogens from the precursor methane molecule has become chemically equivalent to the hydrogen accepted in the formation (see eq 1).

It was established earlier that under conditions such as in the present study protonated methane is formed dominantly via a proton transfer from ionized methane to methane [6] (see above), so it may be concluded that during the formation the proton has inserted into one of the $\sigma \mathrm{C}-\mathrm{H}$ bonds of methane to form a symmetric three-center two-electron bond with the carbon and the hydrogen atom, such as in the theoretically predicted structure $[10,12-14]$ visualized 


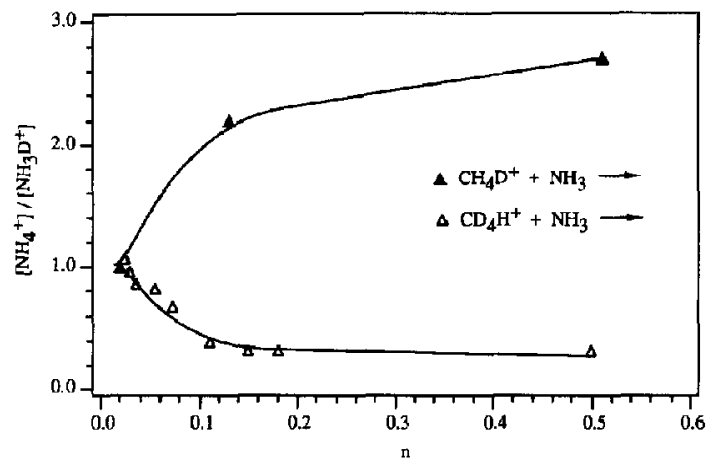

Figure 3. Product ion ratio $\left[\mathrm{NII}_{4}^{+}\right] /\left[\mathrm{NH}_{3} \mathrm{D}^{+}\right]$associaled wilh the proton/deuteron transfer reaction of $\mathrm{CH}_{4} \mathrm{D}^{+}(\Lambda)$ and $\mathrm{CD}_{4} \mathrm{H}^{+}(\Delta)$ to ammonia, determined as a function of the average number of primary ion/molecule collisions, $n$, in the external ion source. The error in the product ion ratios is estimated to be less than $10 \%$ (see text).

in Figure 1. Furthermore, the results demonstrate that the acidity of protonated methane is restricted to the ability to exclusively transfer one of the two hydrogens that are associated in the three-center two-electron bond.

Evidently, no intramolecular or intermolecular hydrogen deuterium exchange has taken place in the reaction complex resulting in the formation of protonated methane as well as in the reaction complex resulting in the proton transfer from protonated methane to ammonia. Yet, the results in Figure 3 indicate that the hydrogens in protonated methane lose their original identity if the average number of collisions between ionized methane and methane is increased, and thus the probability of secondary collisions between protonated methane and methane is enhanced. Apparently, these secondary collisions initiate hydrogen/deuterium randomization. It can be excluded that this randomization is the result of intermolecular thermoneutral hydrogen/deuterium exchange within the collision complex because such a process would have resulted in additional formation of both $\mathrm{CH}_{3} \mathrm{D}_{2}^{+}$and $\mathrm{CH}_{2} \mathrm{D}_{3}^{+}$ions, which have not been observed. This intermolecular hydrogen/deuterium exchange is known to be inefficient with a reaction rate constant below $2.5 \times 10^{-10} \mathrm{~cm}^{3}$ molecule ${ }^{-1} s^{-1}[22]$

If the collisionally induced intramolecular randomization results in a statistical distribution of hydrogen and deuterium in the isotopically labeled protonated methanes, it is expected that $\mathrm{CH}_{4} \mathrm{D}^{+}$prefers proton over deuteron transfer to ammonia by a factor of 4 . whereas for $\mathrm{CD}_{4} \mathrm{H}^{+}$this factor has reduced to 0.25 . This behavior is indeed observed as may be evident from the results in Figure 3, which show that for the reaction with $\mathrm{CH}_{4} \mathrm{D}^{+}$the product ion ratio $\left[\mathrm{NH}_{4}^{+}\right] /\left[\mathrm{NH}_{3} \mathrm{D}^{+}\right]$progresses from 1 toward 4 upon increasing the average number of primary ion colli- sions, whereas for the reaction with $\mathrm{CD}_{4} \mathrm{H}^{+}$this ratio tapers off from 1 toward 0.25 .
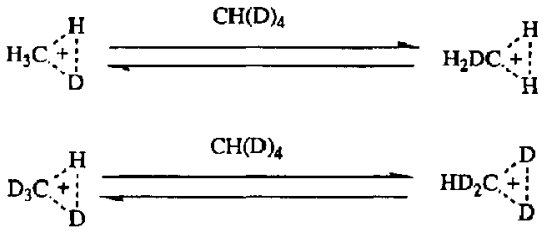

If $80 \%$ of the randomized and $50 \%$ of the nonrandomized $\mathrm{CH}_{4} \mathrm{D}^{+}$ions transfer a proton to ammonia and, likewise $20 \%$ of the randomized and $50 \%$ of the nonrandomized $\mathrm{CD}_{4} \mathrm{H}^{+}$ions transfer a proton to ammonia, than the bimolecular rate constant for the collisionally induced intramolecular randomization follows from the $\left[\mathrm{NH}_{4}^{+}\right] /\left[\mathrm{NH}_{3} \mathrm{D}^{+}\right]$product ion ratio as a function of the number of primary ion collisions, $\mathrm{n}$ (or the pressure) in Figure 3. This reveals that the randomization (eq 3 ) is a very fast process of which the bimolecular rate constant is estimated to be five to eight times larger than the rate constant for the orbiting collisions, $\mathrm{k}_{\mathrm{ADO}}$, between $\mathrm{CH}_{5}^{+}$and $\mathrm{CH}_{4}$. This would indicate that the interconversion of protonated methane does not necessarily have to be induced by orbiting collisions but can already be induced by weak interactions between the protonated methane and methane.

In conclusion, the chemical behavior of protonated methane appears to be compatible with the theoretically predicted stable structure with $\mathrm{C}_{\mathrm{s}}$ symmetry, involving a three-center two-electron bond associating two hydrogens and the carbon atom. Interconversion of this structure due to exchange between one of these hydrogens and one of the three remaining hydrogens appears to be a fast process that is induced by interactions with the chemical ionization gas.

\section{References}

1. Tal'roze, V. L.; Lyubimova, A. K. Dokl. Akad. Nauk. SSSR 1952, 86, 909 .

2. Stevenson, D. P.; Schissler, D. O. J. Chem. Phys. 1955, 23, 1353.

3. (a) Hogeveen, H.; Gaasbeek, C. J. Recl. Trav. Chim. Pays-Bas 1968, 87, 319. (b) Olah, G. A.; Klopman, G.; Schlosberg, R H. J. Am. Chem. Soc. 1969, 91, 3261. (c) Olah, G. A. Chem Brit. 1972, 8, 281.

4. (a) Munson, M. S. B.; Field, F. H. J. Am. Chem. Soc. 1966, 88, 2621. (b) Harrison, A. G. Chemical Ionization Mass Spectrometry; CRC Press; Boca Raton, FL, 1983.

5. (a) Wagner, C. D.; Wadsworth, P. A.; Stevenson, D. P. I. Chem. Phys. 1958, 28, 517. (b) Abramson, F. P.; Futrell, J. H. J. Chem. Phys. 1966, 45, 1925. (c) Huntress, W. T. Jr. I. Chem. Phys. 1972, 56, 5111.

6. Herman, Z.; Henchman, M.; Friedrich, B. I. Chem. Phys $1990,93,4916$.

7. (a) Herman, Z.; Tanaka, K.; Kato, T.; Koyano, I. J. Chem Phys. 1986, 85, 5705. (b) Herman, Z.; Koyano, 1. I. Chem. Soc. Furaday Trans. 2 1987, 83, 127.

8. Henchman, M.; Smith, D.; Adams, N. G.; Paulson, J. F.; 
Herman, Z. Int. J. Mass Spectrom. Ion. Processes 1989, 92, 15.

9. Smith, D.; Adams, N. C. Chem. Phys. Lett. 1989, 161, 30.

10. Pople, J, A. Int. I. Mass Spectrom. Ion Phys. 1976, 19, 89.

11. Wong, M. W.; Radom, L. J. Am. Chem. Soc. 1989, 111, 1155.

12. (a) Gamba, A.; Morosi, G.; Simonetta, M. Chem. Phys. Lett. 1969, 3, 20. (b) Dyczmons, V.; Staemmler, V.; Kutzelnigg. W. Chem. Phys, Lett. 1970, 5, 361. (c) Hariharan, P. C. Lathan, W. A.; Pople, J. A. Chem. Phys. Lett. 1972, 14, 385.

13. Hirao, K.; Yamabe, S. Chem. Phys. 1984, 89, 237.

14. Komornicki, A.; Dixon, D. A. J. Chem. Phys. 1987, 86, 5625.

15. Sefrik, M. D.; Henis, J. M. S.; Gaspar, P. P. J. Chem. Phys. 1974, 61, 4321 .

16. Smith, R. D.; Futreli, J. H. Chem. Phys. Lett. 1975, 36, 545.
17. Smith, D. L; Futrell, J. H. Int. J. Mass Spectrom. Ion Phys. 1974, 14, 171.

18. de Koning, L. J.; Fokkens, R. H.; Pinkse, F. A.; Nibbering, N. M. M. Int. J. Mass Spectrom. Ion Processes 1987, 77, 95.

19. Heck, A. J. R.; Drewello, T; de Koning, L. J.; Nibbering, N. M. M. Int. I. Mass Spectrom. Ion Processes 1990, 100, 611.

20. Lias, S. G.; Bartmess, J. E.; Liebman, J. F.; Holmes, J. L.; Levin, R. D.; Mallard, W. G. J. Phys. Chem. Ref. Data 1988, 17, Suppl. 1.

21. (a) Su, T,; Bowers, M. T. Int. I. Mass Spectrom. Ion Phys. 1973, 12, 347. (b) Lindinger, W.; Albritton, D. L.; Fehsenfeld, F. C.; Schmeltenkopf, A. L.; Ferguson, E. E. 1. Chem. Phys. 1975, 6?, 3549 .

22. Adams, N. G.; Smith, D.; Henchman, M. J. Int. J. Mass Spectrom. Ion Processes 1982, 42, 11. 